\title{
Design and Simulation on Information Providing Service for Temporary Voluntary Organizations
}

\author{
Tetsuya Oishi, Rieko Fujita and Tokuro Matsuo*
}

\begin{abstract}
To get more benefit, most of all organizations gather and analyze various data. Especially, these systems work well in profit-making organizations. In recent years, universities which are permanently voluntary organizations became active in order to know themselves. However, there are no such systems in temporary voluntary organizations. Therefore, these organizations cannot always decide something correctly. In this paper, we not only design a mechanism to solve this problem occurred in temporary voluntary organizations but also simulate this mechanism by using simple example.
\end{abstract}

Keywords: Information Providing, Temporary Voluntary Organizations

\section{Introduction}

In recent year, we have become to be able to analyze a large-scale data because Information and Communication Technology (ICT for short) has been highly developing. Most of organizations as well as end users store various data in their computers. Computer users can analyze various data individually by their own Personal Computers (PCs for short) which have high performance hardware. Most of all profit organizations had stored data to get more benefit by analyzing it. For example, these data include number of staffs, number of branches, advertisements, clients attributes and behaviors, income and profits, and so on. Voluntary associations and organizations have some difficulties to analyze that kind of data and to make a strategy for their management due to few analysts in the organizations even though they have such data. Research institutes and universities which do not pursue profits improve their conditions, performances, management, and so on by using the method of Institutional Research (IR for short).

This method is available for temporary voluntary associations and organizations. For example, we assume that there are the people who live in a local community and they have to decide to hold a festival, to sell special products, or to build new institutions. In this case, they will create temporary organizations. Usually, these organizations will be voluntary. These similar temporary voluntary organizations exist in the world. However, a decision that is produced from a temporary voluntary organization hardly contribute to the other similar organizations. It is very hard to provide a temporary voluntary organization with the information created by the other organizations because there are no such systems. In

* Advanced Institute of Industrial Technology, Tokyo, Japan 


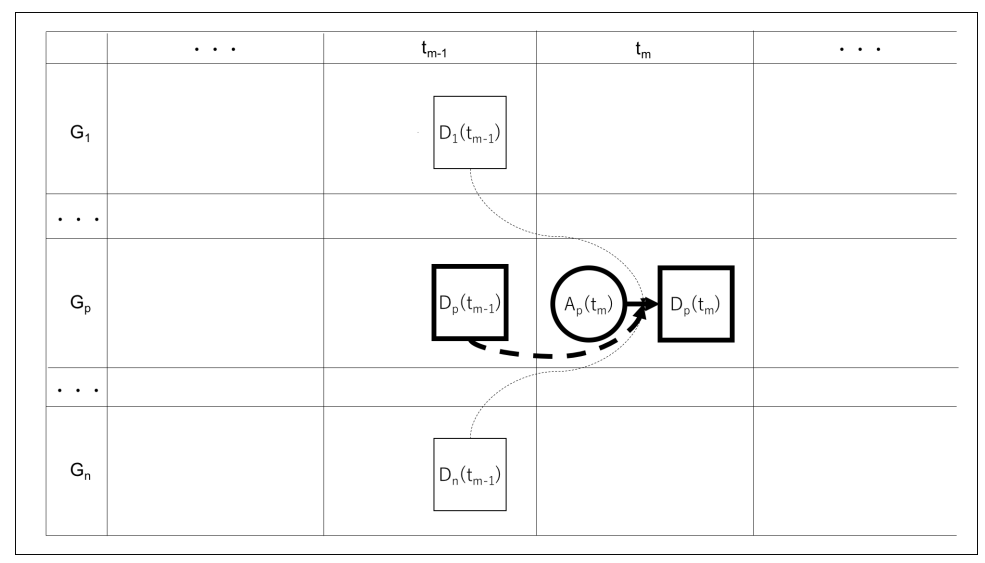

Figure 1: Traditional Mechanism

this paper, we design a method to provide such temporary voluntary organizations with available information to obtain the best decisions.

\section{Preliminary}

\subsection{Cases based on Experiences}

There is the influence of leadership soft skill with school improvement [1]. This skill include communication skill to gather various data. In other words, organizations having no soft skills will be ruined. For example, universities in USA raise donation for their better performance and management after using data [2].

\subsection{Institutional Research}

Many permanently voluntary associations and organizations exist. University is one of these organizations. Universities must check themselves on the aspects like scientific research, education, and social contribution. Many universities pay attention to Institutional Research (IR for short). IR is used to support institutional planning, decision-making and improvement by providing information and its analysis [3]. To share and co-develop informational systems to gather various data, virtual environments were introduced [4][5]. To gather various data from students and teachers, some questionnaire survey systems were introduced in many universities [6][7]. These are activities of IR.

\section{Design}

In this section, we show a design on information providing service for temporary groups. These groups mean organizations and associations. We explain the traditional mechanism and propose our design. 


\subsection{Traditional Mechanism}

We assume that a temporary voluntary group exist independently. The group can use its own information to decide something. Unfortunately, the group hardly uses the information provided by the other groups because there are no services providing information one another. The group can only use its own attributes and its own previous decision. The following formula represent the situation.

$$
D_{p}\left(t_{m}\right)=F_{p}\left(A_{p}\left(t_{m}\right), D_{p}\left(t_{m-1}\right)\right)
$$

Here, the symbols used in the formula (1) are as follows.

- $D_{p}\left(t_{m}\right)$ means the decision that the temporary voluntary group $G_{p}$ can obtain at the time $t_{m}$.

- $F_{p}$ means the function as a process of the discussion in that a temporary voluntary group $G_{p}$ using $A_{p}\left(t_{m}\right)$ and $D_{p}\left(t_{m-1}\right)$.

- $A_{p}\left(t_{m}\right)$ means the attributes that the temporary voluntary group $G_{p}$ originally has at the time $t_{m}$.

- $D_{p}\left(t_{m-1}\right)$ means the decision that the temporary voluntary group $G_{p}$ obtained at the time $t_{m-1}$.

- $t_{m-1}$ means the previous time of the time $t_{m}$.

$A_{p}\left(t_{m}\right)$ affects the decision $D_{p}\left(t_{m}\right)$ greatly because the group $G_{p}$ cannot use the information from the other groups. Figure 1, which consists of a circle, squares, and arrows, explains the formula (1). Here, the circle means the attribute, the squares mean the decisions, the broken arrows mean the effects on the decisions by the decisions of the other groups, and the solid arrows mean the effects on the decisions by the attribute. The thin arrows mean the attributes and the decisions influence the decision indirectly, for example, rumor, entries of blogs, and so on. The thick arrows mean the attributes and the decisions affect the decision directly, for example, number and sort of participants, fund of the group, opinions created from the group, and so on.

\subsection{Proposed Service}

We assume that $n$ temporary voluntary groups exist. The proposed service is greatly different from the traditional mechanism mentioned in Section 3.1. One of these temporary voluntary groups can use not only its own data but also the data from other organizations in order to decide something. The following formula represent the situation.

$$
D_{p}\left(t_{m}\right)=F_{p}\left(A_{p}\left(t_{m}\right), \bigcup_{j=1}^{n} D_{j}\left(t_{m-1}\right)\right)
$$

Here, the symbols used in the formula (2) are as follows.

- $D_{p}\left(t_{m}\right)$ is the decision that a temporary voluntary group $G_{p}$ can obtain at the time $t_{m}$. The group $G_{p}$ is one of similar temporary voluntary groups. The number of these groups is $n$. 


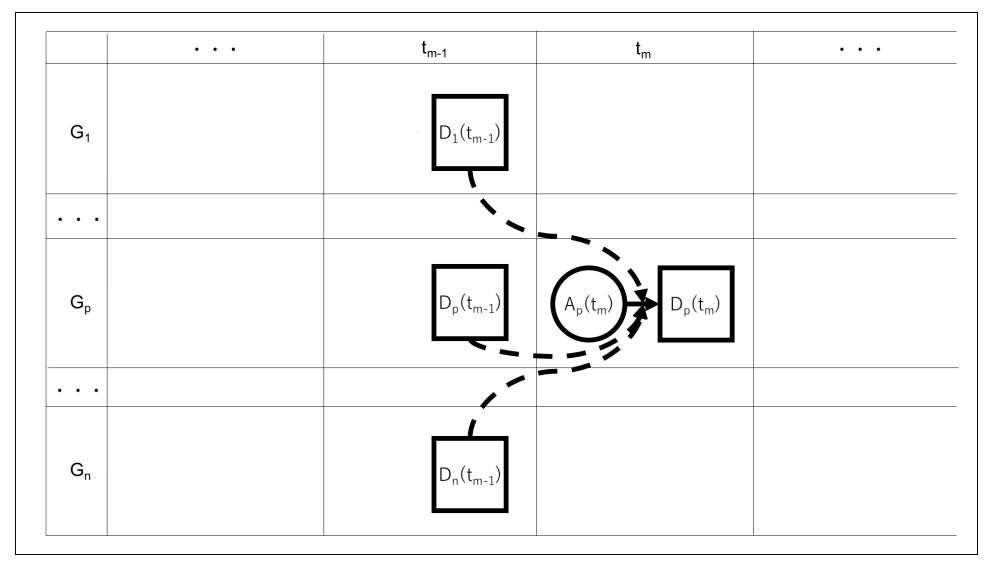

Figure 2: Proposal Mechanism

- $F_{p}$ means the function as a process of a discussion in that a temporary voluntary group $G_{p}$ using $A_{p}\left(t_{m}\right)$ and $D_{j}\left(t_{m-1}\right)$ where $j=1, \cdots, n$.

- $A_{p}\left(t_{m}\right)$ means the attributes that a temporary voluntary group $G_{p}$ originally has at the time $t_{m}$.

- $D_{j}\left(t_{m-1}\right)$ means the decision that a temporary voluntary group $G_{j}$ obtained at the time $t_{m-1}$.

- $t_{m-1}$ means the previous time of the time $t_{m}$

The decision $D_{p}\left(t_{m}\right)$ is greatly affected by $A_{p}\left(t_{m}\right)$ and $D_{j}\left(t_{m-1}\right)$ where $j=1, \cdots, n$. In our proposed service, a group can use the data from own and other decisions at the time $t_{m-1}$ when the group decides something at the time $t_{m}$. Figure 2, where the symbols used in the figure are same as the ones mentioned in Section 3.1, explains formula (2). Our service enables a group to decide something precisely by providing not only own data but also data obtained from other groups.

\section{Conceptual Simulation}

In this section, we show a conceptual simulation using our service. We assume that three temporary voluntary groups $\left(G_{1}, G_{2}\right.$, and $G_{3}$ shown in Table 1$)$ exist. These groups intend to decide whether their reunion should be held. Each group has number of committee members, estimate number of participants, and initial capital as attributes .

\subsection{Discussion in $G_{1}$ at time $t_{0}$}

There are no own and other decisions. Therefore, the formula (3) shows that the group $G_{1}$ starts discussing at time $t_{0}$ with only its own attributes $\left(A_{1}\left(t_{0}\right)\right)$.

$$
D_{1}\left(t_{0}\right)=F_{1}\left(A_{1}\left(t_{0}\right), \emptyset\right)
$$

Figure 3 shows that $G_{1}$ could decide nothing at $t_{0}$. That is to say, $D_{1}\left(t_{0}\right)$ means "undecided". 
Table 1: Assumption and Final Decision in Conceptual Simulation

\begin{tabular}{|c||r|r|r||c|}
\hline \multicolumn{1}{|c||}{} & \multicolumn{3}{c||}{ attributes } & \\
\cline { 2 - 5 } group & $\begin{array}{c}\text { number } \\
\text { of } \\
\text { number } \\
\text { committee } \\
\text { members }\end{array}$ & $\begin{array}{c}\text { estimate } \\
\text { number } \\
\text { of } \\
\text { participants }\end{array}$ & $\begin{array}{c}\text { initial } \\
\text { capital }\end{array}$ & $\begin{array}{c}\text { final } \\
\text { decision }\end{array}$ \\
\hline$G_{1}$ & 10 & 600 & $\$ 1,000$ & held \\
\hline$G_{2}$ & 10 & 100 & $\$ 300$ & not held \\
\hline$G_{3}$ & 10 & 300 & $\$ 2,000$ & held \\
\hline
\end{tabular}

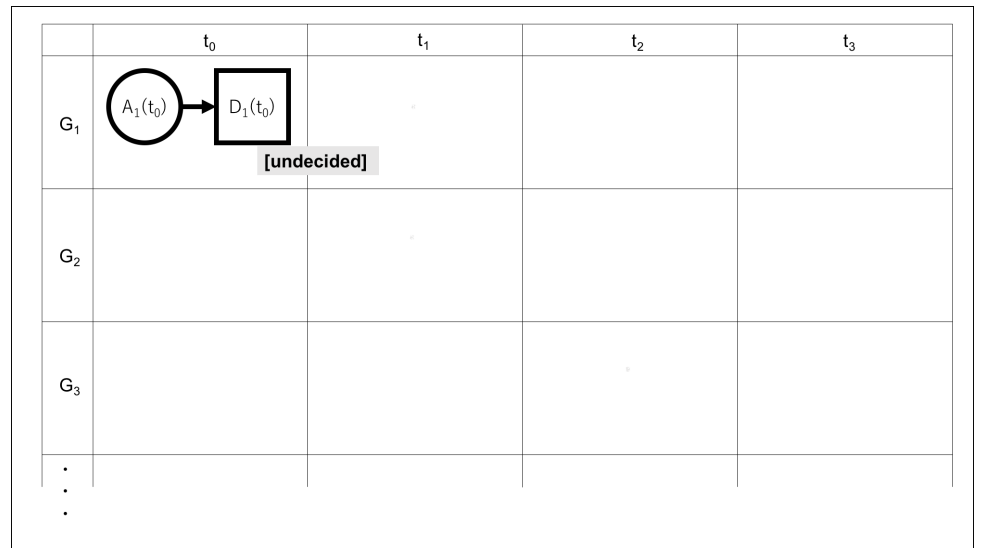

Figure 3: Discussion in $G_{1}$ at time $t_{0}$

\subsection{Discussions in $G_{1}$ and $G_{2}$ at time $t_{1}$}

The formula (4) and (5) show that the group $G_{1}$ and $G_{2}$ start discussing at time $t_{1}$ with these own attributes $\left(A_{1}\left(t_{1}\right)\right.$ and $\left.A_{2}\left(t_{1}\right)\right)$ and the decision $\left(D_{1}\left(t_{0}\right)\right)$, respectively.

$$
\begin{aligned}
& D_{1}\left(t_{1}\right)=F_{1}\left(A_{1}\left(t_{1}\right), D_{1}\left(t_{0}\right)\right) \\
& D_{2}\left(t_{1}\right)=F_{2}\left(A_{2}\left(t_{1}\right), D_{1}\left(t_{0}\right)\right)
\end{aligned}
$$

Figure 4 shows that $G_{1}$ could decide that its reunion would be held at $t_{1}$. That is to say, $D_{1}\left(t_{1}\right)$ means "held". This figure also shows that $G_{2}$ could decide that its reunion would not be held at $t_{1}$. That is to say, $D_{2}\left(t_{1}\right)$ means "not held". The reason why the reunion for $G_{2}$ will not be held, for example, is that there is some fear to be in deficit after holding the reunion because of small estimate number of participants.

\subsection{Discussion in $G_{3}$ at time $t_{2}$}

The formula (6) shows that the group $G_{3}$ starts discussing at time $t_{2}$ with these own attributes $\left(A_{3}\left(t_{2}\right)\right)$ and the decisions $\left(D_{1}\left(t_{1}\right)\right.$ and $\left.D_{2}\left(t_{1}\right)\right)$.

$$
D_{3}\left(t_{2}\right)=F_{3}\left(A_{3}\left(t_{2}\right), D_{1}\left(t_{1}\right) \cup D_{2}\left(t_{1}\right)\right)
$$




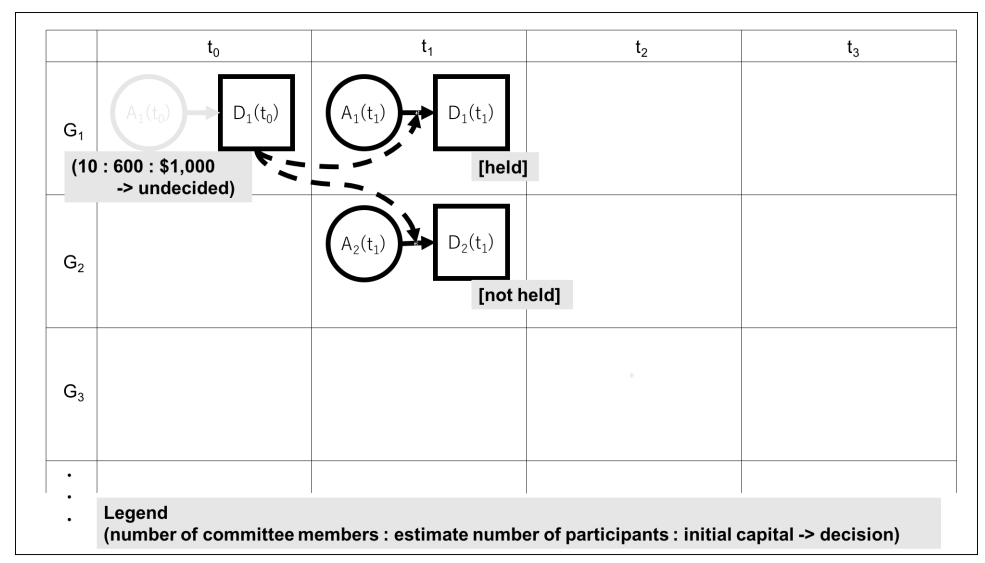

Figure 4: Discussions in $G_{1}$ and $G_{2}$ at time $t_{1}$

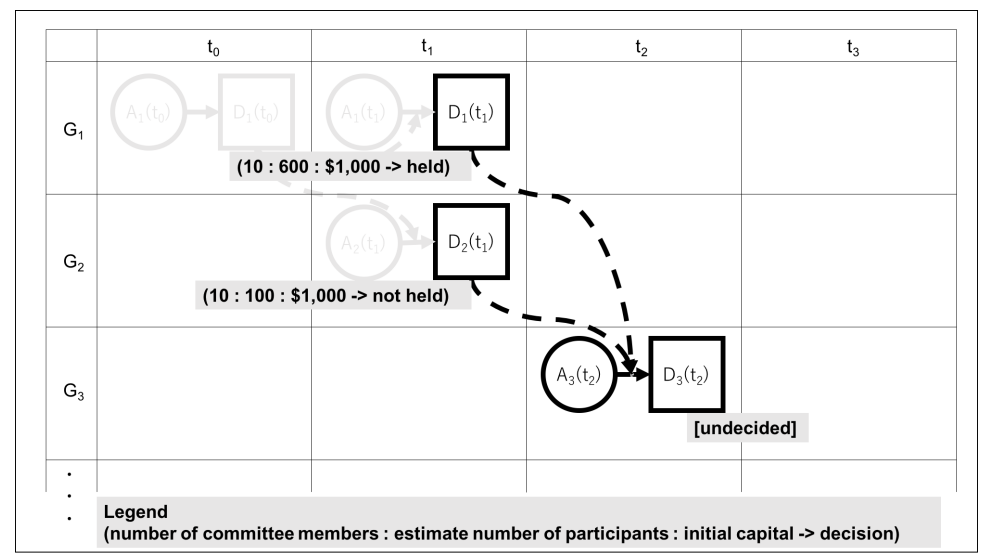

Figure 5: Discussion in $G_{3}$ at time $t_{2}$

Figure 5 shows that $G_{3}$ could decide nothing at $t_{2}$. That is to say, $D_{3}\left(t_{2}\right)$ means "undecided" because $D_{1}\left(t_{1}\right)$ is "held" while $D_{2}\left(t_{1}\right)$ is "not held". Then the group $G_{3}$ put off a decision next time.

\subsection{Discussion in $G_{3}$ at time $t_{3}$}

The formula (7) shows that the group $G_{3}$ starts discussing at time $t_{3}$ with these own attributes $\left(A_{3}\left(t_{3}\right)\right)$ and the decisions $\left(D_{1}\left(t_{2}\right), D_{2}\left(t_{2}\right)\right.$, and $\left.D_{3}\left(t_{2}\right)\right)$.

$$
D_{3}\left(t_{3}\right)=F_{3}\left(A_{3}\left(t_{3}\right), D_{1}\left(t_{2}\right) \cup D_{2}\left(t_{2}\right) \cup D_{3}\left(t_{2}\right)\right)
$$

Here, the formulas $D_{1}\left(t_{2}\right)=D_{1}\left(t_{1}\right)$ and $D_{2}\left(t_{2}\right)=D_{2}\left(t_{1}\right)$ are valid because $D_{1}\left(t_{2}\right)$ and $D_{2}\left(t_{2}\right)$ are same as decisions at $t_{1}$. Figure 6 shows that $G_{3}$ could decide that its reunion would be held at $t_{3}$. That is to say, $D_{3}\left(t_{3}\right)$ means "held". The reason why the reunion for $G_{3}$ will be held, for example, is that there is a firm belief to be in surplus after holding the reunion because of enough estimate number of participants and initial capital.

As mentioned above, following our design, a group can decide something by using the decisions obtained from the other groups. The group $G_{3}$ might decide not to be held 


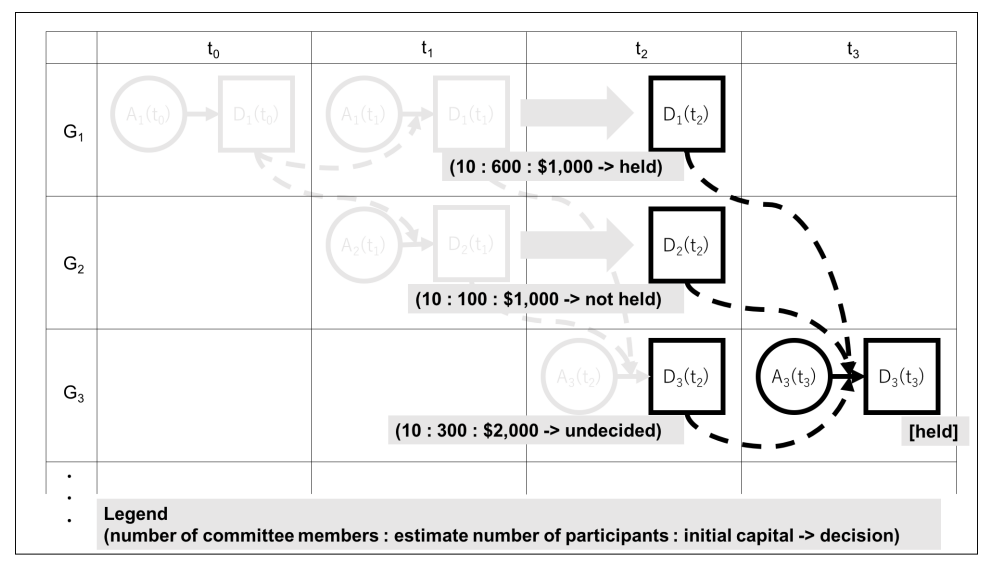

Figure 6: Discussion in $G_{3}$ at time $t_{3}$

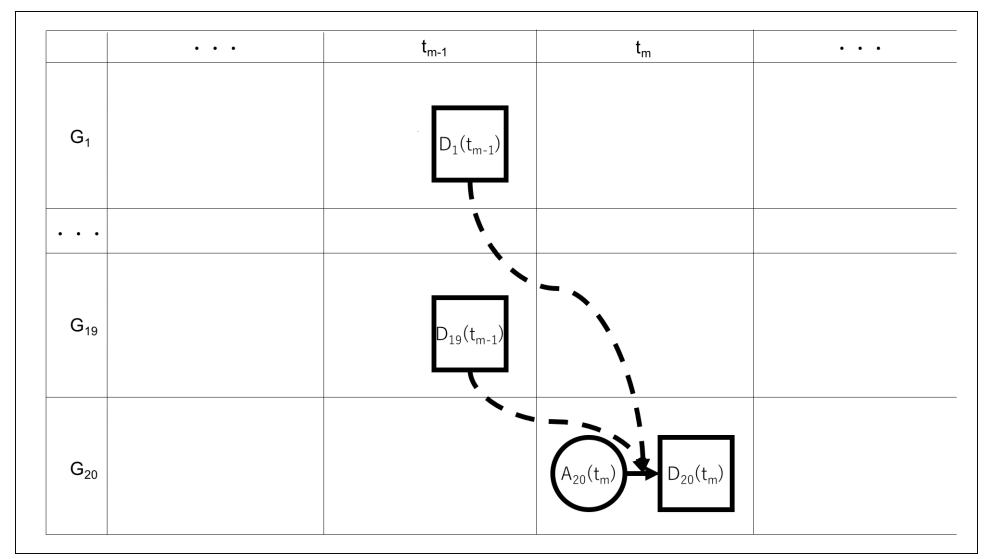

Figure 7: Schematic diagram of simulation by using cosine similarity

reunion even though there are potential to be held reunion in its attributes if the group used traditional mechanism.

\section{Calculative Simulation}

In this section, we show a calculative simulation using our service. We assume that twenty groups exist. All groups have three attributes respectively as shown in Table 2. We also assume that groups from $G_{1}$ to $G_{19}$ have already decided whether they should hold their reunions or not at time $t_{m-1}$. In this condition, we will explain how group $G_{20}$ can decide whether its reunion should be held or not at time $t_{m}$. In Figure 7, we show a schematic diagram of this condition. Moreover, the formula (8) explains the Figure 7.

$$
D_{20}\left(t_{m}\right)=F_{20}\left(A_{20}\left(t_{m}\right), \bigcup_{j=1}^{19} D_{j}\left(t_{m-1}\right)\right)
$$

We use the cosine similarity as $F_{20}$ in the formula (8). We have to define vectors in order to use the cosine similarity. Before we explain the cosine similarity, we will show how to 
Table 2: Assumption and Final Decision in Simulation by Cosine Similarity $\left(x_{i, j}\right)$

\begin{tabular}{|c|c|c|c|c|}
\hline \multirow[b]{2}{*}{$\begin{array}{l}\text { group } \\
\text { number }\end{array}$} & \multicolumn{3}{|c|}{ attributes } & \multirow[b]{2}{*}{$\begin{array}{c}\text { final } \\
\text { decision }\end{array}$} \\
\hline & $\begin{array}{c}\text { number } \\
\text { of } \\
\text { committee } \\
\text { members } \\
a_{1}\end{array}$ & $\begin{array}{c}\text { estimate } \\
\text { number } \\
\text { of } \\
\text { participants } \\
a_{2}\end{array}$ & $\begin{array}{c}\text { initial } \\
\text { capital } \\
\quad a_{3}\end{array}$ & \\
\hline$G_{1}$ & 10 & 600 & $\$ 1,000$ & held \\
\hline$G_{2}$ & 10 & 100 & $\$ 300$ & not held \\
\hline$G_{3}$ & 10 & 300 & $\$ 2,000$ & held \\
\hline$G_{4}$ & 10 & 572 & $\$ 1,325$ & held \\
\hline$G_{5}$ & 13 & 604 & $\$ 1,109$ & held \\
\hline$G_{6}$ & 18 & 429 & $\$ 256$ & not held \\
\hline$G_{7}$ & 4 & 82 & $\$ 1,449$ & not held \\
\hline$G_{8}$ & 12 & 488 & $\$ 443$ & not held \\
\hline$G_{9}$ & 12 & 613 & $\$ 1,686$ & held \\
\hline$G_{10}$ & 15 & 402 & $\$ 1,722$ & held \\
\hline$G_{11}$ & 18 & 230 & $\$ 245$ & not held \\
\hline$G_{12}$ & 14 & 259 & $\$ 1,146$ & not held \\
\hline$G_{13}$ & 10 & 743 & $\$ 288$ & held \\
\hline$G_{14}$ & 12 & 170 & $\$ 451$ & not held \\
\hline$G_{15}$ & 19 & 215 & $\$ 1,077$ & not held \\
\hline$G_{16}$ & 2 & 224 & $\$ 1,047$ & not held \\
\hline$G_{17}$ & 12 & 700 & $\$ 460$ & held \\
\hline$G_{18}$ & 4 & 737 & $\$ 1,975$ & held \\
\hline$G_{19}$ & 18 & 372 & $\$ 1,129$ & held \\
\hline $\mathbf{G}_{20}$ & 19 & 191 & $\$ 414$ & undecided \\
\hline
\end{tabular}

make vectors.

\subsection{Making Vector}

We treat values shown in Table 2 as numeric values simply. First, we define that $x_{i, j}$ is the value of the attribute $a_{i}$ for group $G_{j}$. Here, $a_{1}$ means the number of committee members, $a_{2}$ means the estimate number of participants, and $a_{3}$ means the initial capital as shown in Table 2.

High value appeared in a vector can influence the cosine similarity we will mention later. The elements of the vector are the values of attributes since we would like to make vectors for every group. For example, the attribute $a_{3}$ will greatly influence the cosine similarity because the values shown in $a_{3}$ are higher than the other attributes in Table 2 . Therefore, after normalizing $x_{i, j}$, we calculate $x_{i, j}^{\prime}$.

We use the standard deviation in order to normalize $x_{i, j}$. First we have to calculate $\overline{x_{i}}$ which is the average of values for attribute $a_{i}$ and $s_{i}$ which is the standard deviation of values 
Table 3: Normalization of Attributes in Table $2\left(x_{i, j}^{\prime}\right)$

\begin{tabular}{|c|c|c|c|c|}
\hline \multirow[b]{2}{*}{$\begin{array}{l}\text { group } \\
\text { number }\end{array}$} & \multicolumn{3}{|c|}{ attributes } & \multirow[b]{2}{*}{$\begin{array}{c}\text { cosine } \\
\text { similarity } \\
\text { with } \\
G_{20}\end{array}$} \\
\hline & $\begin{array}{c}\text { number } \\
\text { of } \\
\text { committee } \\
\text { members } \\
a_{1}\end{array}$ & $\begin{array}{c}\text { estimate } \\
\text { number } \\
\text { of } \\
\text { participants } \\
a_{2}\end{array}$ & $\begin{array}{c}\text { initial } \\
\text { capital } \\
a_{3}\end{array}$ & \\
\hline$G_{1}$ & -0.434 & 0.936 & 0.041 & -0.772 \\
\hline$G_{2}$ & -0.434 & -1.422 & -1.171 & 0.513 \\
\hline$G_{3}$ & -0.434 & -0.479 & 1.774 & -0.497 \\
\hline$G_{4}$ & -0.434 & 0.804 & 0.604 & -0.919 \\
\hline$G_{5}$ & 0.186 & 0.955 & 0.230 & -0.455 \\
\hline$G_{6}$ & 1.220 & 0.129 & -1.248 & 0.811 \\
\hline$\overline{G_{7}}$ & -1.675 & -1.507 & 0.819 & -0.354 \\
\hline$G_{8}$ & -0.021 & 0.408 & -0.924 & 0.231 \\
\hline$G_{9}$ & -0.021 & 0.997 & 1.230 & -0.703 \\
\hline$G_{10}$ & 0.600 & 0.002 & 1.292 & -0.143 \\
\hline$G_{11}$ & 1.220 & -0.809 & -1.267 & 0.979 \\
\hline$G_{12}$ & 0.393 & -0.672 & 0.294 & 0.568 \\
\hline$G_{13}$ & -0.434 & 1.611 & -1.192 & -0.259 \\
\hline$G_{14}$ & -0.021 & -1.092 & -0.910 & 0.685 \\
\hline$G_{15}$ & 1.427 & -0.880 & 0.175 & 0.816 \\
\hline$G_{16}$ & -2.088 & -0.838 & 0.123 & -0.505 \\
\hline$G_{17}$ & -0.021 & 1.408 & -0.894 & -0.168 \\
\hline$G_{18}$ & -1.675 & 1.582 & 1.731 & -0.983 \\
\hline$G_{19}$ & 1.220 & -0.139 & 0.265 & 0.648 \\
\hline $\mathbf{G}_{20}$ & 1.427 & -0.993 & -0.974 & 1.000 \\
\hline
\end{tabular}

for attribute $a_{i} . \overline{x_{i}}$ and $s_{i}$ are calculated by the formula (9) and (10) respectively.

$$
\begin{gathered}
\overline{x_{i}}=\frac{1}{n} \sum_{j=1}^{n} x_{i, j} \\
s_{i}=\sqrt{\frac{1}{n} \sum_{j=1}^{n}\left(x_{i, j}-\overline{x_{i}}\right)^{2}}
\end{gathered}
$$

Here, $n$ is the total number of groups, that is, $n=20 . x_{i, j}^{\prime}$ is calculated by using $x_{i, j}, \overline{x_{i}}$, and $s_{i}$ as shown in formula (11).

$$
x_{i, j}^{\prime}=\frac{x_{i, j}-\overline{x_{i}}}{s_{i}}
$$

We make vectors $V_{G_{j}}(j=1, \cdots, 20)$ which are consisted by $x_{i, j}^{\prime}$ for group $G_{j}$ as shown in Table 3. $V_{G_{j}}$ is shown in formula (12) because there are three attributes which are $a_{1}, a_{2}$, and $a_{3}$ in our situation.

$$
V_{G_{j}}=\left(x_{1, j}^{\prime}, x_{2, j}^{\prime}, x_{3, j}^{\prime}\right)
$$


Table 4: Comparing $G_{11}$ with $G_{20}$

\begin{tabular}{|c|c|c|c|c|}
\hline \multirow[b]{2}{*}{$\begin{array}{l}\text { group } \\
\text { number }\end{array}$} & \multicolumn{3}{|c|}{ attributes } & \\
\hline & $\begin{array}{c}\text { number } \\
\text { of } \\
\text { committee } \\
\text { members } \\
a_{1}\end{array}$ & $\begin{array}{c}\text { estimate } \\
\text { number } \\
\text { of } \\
\text { participants } \\
a_{2}\end{array}$ & $\begin{array}{c}\text { initial } \\
\text { capital } \\
a_{3}\end{array}$ & $\begin{array}{c}\text { final } \\
\text { decision }\end{array}$ \\
\hline$G_{11}$ & 18 & 230 & $\$ 245$ & not held \\
\hline$G_{18}$ & 4 & 737 & $\$ 1,975$ & held \\
\hline$G_{20}$ & 19 & 191 & $\$ 414$ & undecided \\
\hline
\end{tabular}

\subsection{Cosine Similarity}

We calculate $\operatorname{Sim}\left(V_{G_{p}}, V_{G_{q}}\right)$ which is a cosine similarity between group $G_{p}$ and group $G_{q}$. $\operatorname{Sim}\left(V_{G_{p}}, V_{G_{q}}\right)$ is calculated by using formula (13).

$$
\operatorname{Sim}\left(V_{G_{p}}, V_{G_{q}}\right)=\frac{V_{G_{p}} \cdot V_{G_{q}}}{\left|V_{G_{p}}\right|\left|V_{G_{q}}\right|}
$$

Here, $V_{G_{p}} \cdot V_{G_{q}}$ and $\left|V_{G_{j}}\right|$ are calculated by using formula (14) and (15) respectively.

$$
\begin{gathered}
V_{G_{p}} \cdot V_{G_{q}}=x_{1, p}^{\prime} \cdot x_{1, q}^{\prime}+x_{2, p}^{\prime} \cdot x_{2, q}^{\prime}+x_{3, p}^{\prime} \cdot x_{3, q}^{\prime} \\
\left|V_{G_{j}}\right|=\sqrt{{x_{1, j}^{\prime}{ }^{2}+x_{2, j}^{\prime}+x_{3, j}^{\prime 2}}^{2}}
\end{gathered}
$$

\subsection{Decision for group $G_{20}$}

We compare group $G_{20}$ with other nineteen groups by using formula (13). On the most right line in Table 3, the cosine similarities with group $G_{20}$ are shown. $\operatorname{Sim}\left(V_{G_{p}}, V_{G_{q}}\right)=1$ means that vectors $V_{G_{p}}$ and $V_{G_{q}}$ turn in the same direction, that is, $V_{G_{p}}$ is most similar to $V_{G_{q}}$. Conversely, $\operatorname{Sim}\left(V_{G_{p}}, V_{G_{q}}\right)=-1$ means that vectors $V_{G_{p}}$ and $V_{G_{q}}$ turn in the opposite direction, that is, $V_{G_{p}}$ is most different from $V_{G_{q}}$.

What we have to do is to find the cosine similarity that is the most nearly 1 in Table 3 . We can find group $G_{11}$ that has the cosine similarity 0.979 with group $G_{20}$. We can also find group $G_{18}$ that has the cosine similarity -0.983 with group $G_{20}$. Then we verify whether group $G_{20}$ is really similar to group $G_{11}$, and whether group $G_{20}$ is not really similar to group $G_{18}$.

Table 4 contains group $G_{11}, G_{18}$, and $G_{20}$ which are picked out from Table 2. We can understand that group $G_{20}$ is surely similar to $G_{11}$ and group $G_{20}$ is not also similar to group $G_{18}$.

From these verification, group $G_{20}$ can decide whether their reunion should be held by using the decision of $G_{11}$. Group $G_{11}$ had already decided that their reunion was not held. Then, in this simulation, group $G_{20}$ is proposed that their reunion should not be held.

\section{Discussion}

In this section, we discuss how the service we designed in Section 3 is realized. 


\subsection{Distributed Database}

In recent year, distributed databases are developed [8][9]. These databases can have attributes and decisions of every group. The analysis of stored data can vary the final decisions. There are two analyses: one is comparison between similar groups and another is observation of estrangement from average of all groups. The stored data are still distributed when similar groups are compared each other. Wrong decisions can be implied because the groups that are not similar to each other are ignored even if these ignored groups may have useful data. We can know the average of all data if all distributed data can be gathered together. Comparing own data with average data, each group can obtain suitable information.

\subsection{Information Recommendation}

In our design, some facts which are obtained from every temporary voluntary group for similar purpose can be used. Not only the facts are provided to each group, but also some proposals can be recommended by implying these facts [10][11]. In each group, several proposals are available instead of deciding something implied from these facts. For example, after entering attributes to the system that realized the function mentioned above, it is very happy that a suitable proposal is recommended.

\section{Conclusion}

In this paper, we explained the design on information providing service for temporary voluntary organizations. Until now, what such organizations could use are only their own information such as their present attributes and previous decisions. Each temporary voluntary organizations can use information from other similar organizations by using this design.

In section 5, we showed a calculative simulation of our design. We used a cosine similarity to support temporary voluntary groups deciding their intentions. The calculation method is available if all attributes can transform numeric values.

Actually, these information are not always received perfectly. In future work, we will pay attention to the loss of information. We will investigate how the receivers use the information sent. Moreover, we will observe how the abilities of the receivers affect the decisions. We will also search for other attributes which we can use in calculative simulation. We would like to do other calculative simulation such as clustering.

\section{Acknowledgments}

This work was supported by CREST, JST.

\section{References}

[1] Tang Keow Ngang, Siti Huwaina Mohamed, and Somprach Kanokorn, "Soft Skills Of Leaders And School Improvement In High Performing Schools", Procedia - Social and Behavioral Sciences, Vol. 191, pp.2127-2131, 2015

[2] Angela Besana and Annamaria Esposito, "Economics and Marketing of USA Universities", Procedia Economics and Finance, Vol. 14, pp.68-77, 2014 
[3] J.L. Saupe, "Functions of Insitutional Research", 2nd Edition, published by Association for Institutional Research, 1990.

[4] Tetsuya Oishi, Masao Mori, and Eiichi Takata, "An Environment to Co-develop Informational Systems for IR in Japan”, Information Engineering Express, Vol. 2, No. 1, pp.55-64, 2016

[5] Tetsuya Oishi, Masao Mori, Toshie Tanaka, and Eisuke Ito, "Cooperative Development and Individual Operation for Information Systems of IR in a Virtual Environment", 2nd International Conference on Institutional Research and Institutional Management (IRIM 2013), 2013

[6] Tetsuya Oishi, Masao Mori, and Eiichi Takata, "A proposal of Human and Machine Reminding for High Response Rate in Use of a Web Questionnaire Survey System", International Journal of Computer \& Information Science, Vol.16, No. 1, pp.22-31, 2015

[7] Satoshi Taoka and Toshimasa Watanabe, "A Web-Based Questionnaire and Its Evaluation of Class-Assessment-by-Students", The Transactions of the Institute of Electronics, Information and Communication Engineers D, Vol_J97-D, No.5, pp. 1024-1034, 2014.

[8] Bernstein, Philip A., and Goodman, Nathan, "Concurrency Control in Distributed Database Systems", ACM Comput. Surv., Vol.13, No.2, pp.185-221, 1981.

[9] Loesing, Simon and Pilman, Markus and Etter, Thomas, and Kossmann, Donald, "On the Design and Scalability of Distributed Shared-Data Databases", Proceedings of the 2015 ACM SIGMOD International Conference on Management of Data, SIGMOD '15, pp.663-676, 2015.

[10] Kenta Oku, Shinsuke Nakajima, Jun Miyazaki, and Shunsuke Uemura, "ContextAware SVM for Context-Dependent Information Recommendation", Proceedings of the 7th International Conference on Mobile Data Management, MDM '06, p.109, 2006.

[11] Ahmed I. Saleh, Ali I. El Desouky, and Shereen H.Ali, "Promoting the Performance of Vertical Recommendation Systems by Applying New Classification Techniques", Know.-Based Syst., Vol.75, No.C, pp.192-223, 2015. 